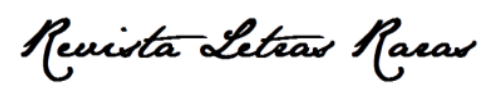

ISSN: 2317-2347 - v. 10, n. 4 (2021)

Todo o conteúdo da RLR está licenciado sob Creative Commons Atribuição 4.0 Internacional

\title{
Narrativas de confluência e a representação de vozes
}

marginalizadas /

\section{Confluence narratives and the representation of}

\author{
marginalized voices
}

Orison Marden Bandeira de Melo Júnior*

Doutor em Linguística Aplicada e Estudos da Linguagem (LAEL/PUC-SP) e professor do curso de LetrasInglês e do Programa de Pós-graduação em Estudos da Linguagem da Universidade Federal do Rio Grande do Norte, Natal, RN, Brasil.

(iD) https://orcid.org/0000-0002-7592-449X

Recebido em: 19 ago. 2021. Aprovado em: 18 dez. 2021.

\section{Como citar esta resenha:}

JÚNIOR, Orison Marden Bandeira de Melo. Narrativas de confluência e a representação de vozes marginalizadas. Revista Letras Raras, Campina Grande, v. 10, n. 4, p. 237-244, dez. 2021.

TOSTA, Antonio Luciano de Andrade. Confluence Narratives: Ethnicity, History, and Nation-Making in the Americas. Lewisburg, PA: Bucknell University Press, 2016. 301p.

Bakhtin, ao escrever em 1970 para a revista Novi Mir sobre a ciência da literatura naquele período, discute a necessidade de conectar passado e presente no processo de estudo da literatura. Para o autor russo, como a literatura é parte inseparável da cultura, ela "não pode ser entendida fora

$\triangle$ orison.junior@ufrn.br

doi http://dx.doi.org/10.35572/rlr.v10i4.2244 


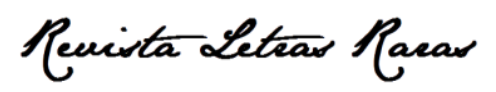

ISSN: 2317-2347 - v. 10, n. 4 (2021)

Todo o conteúdo da RLR está licenciado sob Creative Commons Atribuição 4.0 Internacional

do contexto pleno de toda a cultura de uma época" (BAKHTIN, 2017, p. 11) e, por outro lado, não se pode "fechar o fenômeno literário apenas na época de sua criação" (BAKHTIN, 2017, p. 13), pois as obras "dissolvem as fronteiras da sua época" (BAKHTIN, 2017, p. 13), permitindo, dessa forma, um encontro entre duas culturas. No entanto, segundo Tosta (2016), há obras que já estabelecem esse diálogo entre o passado e o presente, em que o passado é representado de forma crítica a partir de uma perspectiva contemporânea, "conectando passado e presente de forma a revelar causas e consequências, conexões entre eventos precedentes e condições em curso "(p. 20) ${ }^{2}$ - essas obras são as narrativas de confluência.

Confluence Narratives: Ethnicity, History, and Nation-Making in the Americas [Narrativas de confluência: Etnia, História e Formação de Nações nas Américas] é o titulo dado à obra escrita pelo Prof. Dr. Antonio Luciano de Andrade Tosta, professor de Literatura e Cultura Brasileiras da Universidade de Kansas nos Estados Unidos. Mestre em Literatura Comparada pela State University of New York at Buffalo (1999), mestre em Estudos Portugueses e Brasileiros pela Brown University (2002), mestre em Literatura Comparada pela Brown University (2002) e doutor em Literatura Comparada pela Brown University (2006), Tosta é também autor de vários artigos em diversas revistas acadêmicas estadunidenses e estrangeiras, de capítulos de livros e coeditor de dois livros, a saber, Brazil: (Latin America in Focus), publicado em 2015 com Eduardo de Faria Coutinho, e LusoAmerican Literature: Writings by Portuguese-speaking Authors in North America, publicado em 2011 com Robert Henry Moser.

Como é possível perceber, a vida acadêmica e profissional do autor pavimentou o seu caminho para a escrita da riquíssima obra Confluence Narratives: Ethnicity, History, and NationMaking in the Americas, publicada em 2016 pela Editora da Universidade Bucknell. Reconhecendo a necessidade de situar seus leitores dentro da proposta da obra, Tosta explica tanto o uso do termo "confluência", trazendo a palavra latina confluere e seu significado de "fluir junto" (flow together), como a razão pela qual chama as obras que analisa de narrativas de confluência, ou seja, obras que representam e examinam encontros interculturais (cross-cultural) nas Américas, tais como a

\footnotetext{
${ }^{1}$ BAKHTIN, M. A ciência da literatura hoje: (resposta a uma pergunta da revista Novi Mir). In: BAKHTIN, M. Notas sobre literatura, cultura e ciências humanas. Organização, tradução, posfácio e notas de Paulo Bezerra. São Paulo: Editora 34, 2017. p. 9-19.

2 Todas as traduções ao português de citações da obra resenhada são de minha autoria. Texto original: "connect past and present in a way that reveals causes and consequences, links between preceding events and ongoing conditions".
} 


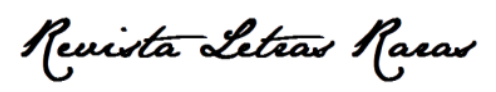

ISSN: 2317-2347 - v. 10, n. 4 (2021)

Todo o conteúdo da RLR está licenciado sob Creative Commons Atribuição 4.0 Internacional

colonização, a escravização e a imigração. Confluência, no entanto, como adverte o autor, não deve ser compreendida como um contrato harmonioso de culturas; pelo contrário, o termo se refere a relações de conflito em que a luta pelo poder é intensificada pelos marcadores sociais de diferença, como raça, etnia e classe (p. 3). Diante disso, para uma compreensão mais precisa da proposta da obra, Tosta traz, ao longo da Introdução, várias discussões acerca do tema, algumas das quais destaco a seguir: "Narrativas de confluência são um subgênero dos romances históricos que examinam identidades nacionais de nações americanas com base em um ou mais de seus encontros culturais" (p. 1)3; "Narrativas de confluência revisitam e reavaliam histórias oficiais [...]. Elas enfatizam a participação e as contribuições de grupos raciais e étnicos marginalizados nas Américas, revelando que raça e etnia são fundamentais para o entendimento da construção de uma identidade nacional na região" (p. 9)4; "esses romances [narrativas de confluência] rejeitam a ideia de uma periferia estática, tendo em vista que grupos marginalizados muitas vezes ocupam uma posição flexível a partir da qual eles [...] se impõem como elementos constituintes significativos da nação" (p. 18)5; "Narrativas de confluência frequentemente revelam versões da história que foram omitidas, disfarçadas ou reprimidas em relatos históricos e literários feitos anteriormente pelas elites dominantes que tradicionalmente controlam a própria história" (p. 20-21)

Tanto no subtítulo da obra quanto nas explicações dadas sobre as narrativas de confluência, percebe-se que o escopo de investigação do autor é a literatura dos continentes americanos. Dessa forma, esse estudo interamericano das narrativas de confluência busca apontar os aspectos comuns das experiências históricas entre países do hemisfério representadas na literatura, reconhecendo as singularidades de suas experiências nacionais e das características próprias de cada literatura nacional (p. 28-29). Nesse sentido, Confluence Narratives participa dos estudos acadêmicos voltados às relações interamericanas, mas traz contribuições significantes ao oferecer uma pesquisa

\footnotetext{
3 Texto original: "Confluence narratives are a subgenre of historical novels that examine the national identities of American nations based on one or more of their cultural encounters".

${ }^{4}$ Texto original: "Confluence narratives revisit and reassess official histories [...]. They emphasize the participation and contributions of marginalized racial and ethnic groups in the Americas, revealing that race and ethnicity are essential to the understanding of the construction of national identity in the region".

${ }^{5}$ Texto original: "these novels reject the idea of a static periphery, as marginal groups often occupy a flexible position from which they $[\ldots]$ impose themselves as meaningful constituents of the nation".

${ }^{6}$ Texto original: "Confluence narratives often reveal versions of history that have been omitted, disguised, or repressed in previous historical and literary accounts by the ruling elites who have traditionally controlled history itself".
} 


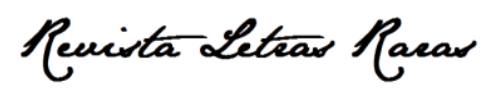

ISSN: 2317-2347 - v. 10, n. 4 (2021)

Todo o conteúdo da RLR está licenciado sob Creative Commons Atribuição 4.0 Internacional

sobre 0 gênero literário 'narrativas de confluência', subgênero dos romances históricos, como elemento central para o estudo tanto de identidades nacionais quanto de uma identidade americana mais ampla (p. 31). Além disso, Tosta esclarece que a obra preenche, também, uma lacuna encontrada nos estudos interamericanos, tendo em vista que traz para o debate o Brasil e a literatura brasileira, apontando para o importante papel que o país desempenha nas Américas ( $p$. 31). Esse papel constitui, dessa forma, a arquitetônica da obra, pois não só o seu conteúdo enfatiza a contribuição e proeminência do Brasil nos estudos interamericanos, como a sua forma, ou seja, a própria estrutura do livro evidencia o diálogo entre uma narrativa de confluência brasileira e uma narrativa de confluência de outra nação americana em cada um dos seus quatro capítulos (p. 32).

Confluence Narratives: Ethnicity, History, and Nation-Making in the Americas contém, nas suas 301 páginas, uma introdução bastante esclarecedora sobre conceitos, posicionamentos, objetivos da obra e sua contribuição, bem como quatro capítulos analíticos, um epílogo em que 0 autor discute outras narrativas de confluência e o futuro dos estudos interamericanos, e elementos pós-textuais, como referências, permissões, índice e informações sobre 0 autor. Cada capítulo traz obras que representam grupos étnicos de acordo com a ordem cronológica da sua existência ou introdução nas Américas: povos indígenas (e a representação da colonização), africanos (e a representação da escravização), judeus (e a representação da imigração) e asiáticos (e a representação de relatos em relação à Segunda Guerra Mundial) (p. 261). Seguindo, portanto, essa ordem proposta pelo autor, o primeiro capítulo analítico traz um diálogo entre a obra Breviário das Terras do Brasil (romance brasileiro) de Luiz Antonio de Assis Brasil e Malinche (romance mexicano) de Laura Esquivel; no segundo, entre a obra A noite dos cristais (romance brasileiro) de Luís Fulano de Tal e Flight to Canada (romance estadunidense) de Ishmael Reed; no terceiro, entre a obra $A$ estranha nação de Rafael Mendes (romance brasileiro) de Moacyr Sclair e Mestizo (romance argentino) de Ricardo Feierstein e, no quarto, entre O súdito: (Banzai, Massateru!) (romance brasileiro) de Jorge J. Okubaro e Obasan (romance canadense) de Joy Kogawa.

O primeiro capitulo, intitulado "The Native American, Hybridity, and Mestiçagem in Luiz Antonio de Assis Brasil's Breviário das Terras do Brasil and Laura Esquivel's Malinche" ["O Indígena Americano, Hibridização e Mestiçagem em Breviário das Terras do Brasil de Luiz Antonio de Assis Brasil e Malinche de Laura Esquivel"] é dividido em quatro seções, a saber, "Native Americans and 


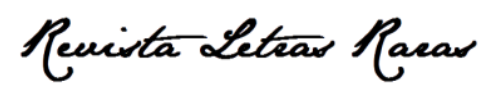

ISSN: 2317-2347 - v. 10, n. 4 (2021)

Todo o conteúdo da RLR está licenciado sob Creative Commons Atribuição 4.0 Internacional

the American nation: between past and present, belonging and exclusion" ["Indígenas americanos e a nação americana: entre o passado e o presente, pertencimento e exclusão"]; "The hybrid Indian and the inescapable coloniality in Luiz Antonio de Assis Brasil's Breviário das Terras do Brasil" ["O indígena híbrido e a colonialidade inescapável em Breviário das Terras do Brasil de Luiz Antonio de Assis Brasil"], "Postcolonial cries amid foundational urges: the reinscription of mestizaje in Laura Esquivel's Malinche" ["Clamores pós-coloniais em meio a impulsos basilares: a reinscrição da mestizaje em Malinche de Laura Esquivel"] e uma conclusão. Após uma discussão sobre povos e nações indígenas tanto no Brasil como no México, Tosta passa a analisar as obras Breviário das Terras do Brasil e Malinche, reconhecendo que seus autores, apesar de não serem descendentes de povos indígenas, criam protagonistas indígenas para "desafiar as posições periféricas em que história os [os povos indígenas] colocou" (p. 40)7. Segundo Tosta, narrativas de confluência como as analisadas neste capítulo "oferecem novas versões do encontro colonial, tratando a autoridade do discurso histórico com desdém e afirmando a proeminência dos indígenas americanos no processo histórico" (p. 40-41)8; dessa forma, ambas as obras baseiam seus enredos em eventos históricos, mas "mostram seu ceticismo sobre o discurso histórico ao apontar as suas omissões" (p. 92) ${ }^{9}$.

O segundo capítulo, intitulado "Escaping the Nation? African American History as (Trans) National History in Luís Fulano de Tal's A noite dos cristais and Ishmael Reed's Flight to Canada" ["Fugindo da Nação? A História Afro-Americana como uma História (Trans)Nacional em A noite dos cristais de Luís Fulano de Tal e Flight to Canada de Ishmael Reed"], é dividido em quatro seções, a saber, "Slavery, African American identity, historical memory, and trauma" ["Escravidão, identidade afro-americana, memória histórica e trauma"]; "National history from an Afro-Brazilian perspective: authorial presence, collective memory, and slavery in A noite dos cristais" ["A história nacional por uma perspectiva afro-brasileira: presença autoral, memória coletiva e escravidão"]; "Demanding collective representation through historical upheaval: slavery, African roots, and African American identity in Flight to Canada" ["Demandando representação coletiva por meio de uma insurreição histórica: escravidão, raízes africanas e identidade afro-americana em Flight to Canada"] e uma

\footnotetext{
${ }^{7}$ Texto original: "challenging the peripheral positions in which history placed them".

8 Texto original: "provide new versions of the colonial encounter, treating the authority of historical discourse with contempt, and asserting the Native American's prominence in the historical process".

${ }^{9}$ Texto original: "show their skepticism toward historical discourse by pointing to its omissions".
} 


\section{Peuista Leteas Pacas}

ISSN: $2317-2347$ - v. 10, n. 4 (2021)

Todo o conteúdo da RLR está licenciado sob Creative Commons Atribuição 4.0 Internacional

conclusão. Por meio de uma discussão sobre a escravização de africanos e africanas em terras americanas, declarando que a escravização "veio a definir uma memória coletiva que assombra o presente" (p. 100)10, para Tosta, os dois romances que analisa denunciam, de forma direta ou indireta, as fontes históricas do racismo que assola a contemporaneidade, e seus autores "exigem um entendimento mais inclusivo e representativo de suas nações e a participação e a importância de africanos-americanos em suas histórias e sociedades" (p. 100)11, "enfatizando o significado do passado, os desafios do presente e a construção do futuro" (p. 144) ${ }^{12}$.

O terceiro capítulo, intitulado "Jewish Puzzels: Identity Search, Memory, and History in Moacyr Sclair's A estranha nação de Rafael Mendes and Ricardo Feierstein's Mestizo" ["Enigmas judaicos: busca por identidade, memória e história em A estranha nação de Rafael Mendes de Moacyr Sclair e Mestizo de Ricardo Feierstein"], é dividido em quatro seções, a saber, "Jewish immigration to the Americas, the search for identity, and the persistence of the nation" ["A imigração judaica nas Américas, a busca por identidade e a persistência da nação"]; "On the path of JewishBrazilian history: identity, recovery in Moacyr Sclair's A estranha nação de Rafael Mendes" ["No caminho da história judaico-brasileira: identidade, recuperação em $A$ estranha nação de Rafael Mendes de Moacyr Sclair"]; "Confluence, otherness, and history in Ricardo Feierstein's Mestizo" ['Confluência, alteridade e história em Mestizo de Ricardo Feierstein"] e uma conclusão. Ao discutir a imigração de judeus nas Américas e o papel significante que tiveram na formação das nações americanas (p. 151), Tosta analisa os dois romances escolhidos para este capítulo, explicando que as obras permitem que os protagonistas "reconstruam o passado, complementem ou mesmo questionem a história e preencham as lacunas de memória" (p. 158) ${ }^{13}$; dessa forma, os protagonistas dessas narrativas de confluência, por estarem "desconectados de suas identidades judaicas" (p. 197)14, precisam "descobrir as suas identidades, a fim de reconstruir a sua posição na sociedade e na nação" (p. 162) ${ }^{15}$.

\footnotetext{
10 Texto original: "has come to define a collective memory that haunts the present".

11 Texto original: "demand a more inclusive and representative understanding of their nations and the participation and importance of African Americans in their histories and societies".

12 Texto original: "highlighting the significance of the past, the challenges of the present, and the construction of the future".

${ }^{13}$ Texto original: "reconstruct the past, to complement or even to question history, and to fill in the gaps of memory".

14 Texto original: "disconnected from their Jewish identities".

15 Texto original: "discover their identities in order to reconstruct their positions in society and in the nation".
} 


\section{Peuista Leteas Pacas}

ISSN: 2317-2347 - v. 10, n. 4 (2021)

Todo o conteúdo da RLR está licenciado sob Creative Commons Atribuição 4.0 Internacional

O quarto capitulo, intitulado "Memory, Difference, and the Struggle for Belonging in Jorge J. Okubaro's O súdito: (Banzai, Massateru!) and Joy Kogawa's Obasan" ["Memória, diferença e a luta pelo pertencimento em $O$ súdito: (Banzai, Massateru!) de Jorge J. Okubaro e Obasan de Joy Kogawa"], é dividido em quatro seções, a saber, "Japanese immigration to the Americas and the mark of difference" ["A imigração japonesa nas Américas e a marca de diferença"]; "Divided loyalties? War, history, ethnic identity, and nationalism in Jorge J. Okubaro's O súdito: (Banzai, Massateru!)" ["Lealdades divididas? Guerra, história, identidade étnica e nacionalismo em 0 súdito: (Banzai, Massateru!) de Jorge J. Okubaro"]; "Reclaiming identity, salvaging history: World War II and the right to voice in Obasan" ["Reivindicando a identidade, salvaguardando a história: a Segunda Guerra Mundial e o direito à voz em Obasan"] e uma conclusão. Ao discutir a imigração japonesa e a incomensurabilidade da sua contribuição nas Américas, e, ao mesmo tempo, explicar o alto nível de preconceito por eles vivido, Tosta, em sua análise das duas narrativas de confluência escolhidas para este capítulo, esclarece que as obras "demonstram como grandes eventos históricos afetam as vidas de pessoas comuns", como a Segunda Guerra Mundial, denunciando como as "diferenças físicas e culturais dos japoneses eram muitas vezes desculpas suficientes para o preconceito" ( $p$. $206)^{16}$. Por outro lado, elas também "usam as vozes dos protagonistas para contar a história de suas famílias e os papéis que tiveram na história nacional" (p. 257)17; diante disso, elas "dão voz ao seu grupo étnico e demandam uma nação mais inclusiva e um discurso nacional que reconheça a diversidade e a pluralidade" (p. 207) ${ }^{18}$.

Vale ressaltar que Confluence Narratives: Ethnicity, History, and Nation-Making in the Americas demostra uma preocupação do autor com a contextualização das obras e, consequentemente, com a familiarização do leitor com o contexto histórico e literário das narrativas analisadas. Para tal, como é possível perceber, cada capítulo se inicia com a apresentação de aspectos históricos dos grupos representados em cada narrativa de confluência e o seu status quo nas Américas. Segundo Tosta, essa apresentação não só dá ao leitor conhecimento necessário para

\footnotetext{
16 Texto original: "demonstrate how larger historical events affect the lives of ordinary people"; "Japanese cultural and physical differences often were sufficient excuses for prejudice".

17 Texto original: "use the voices of single protagonists to tell the stories of their families and the roles they played in national history".

18 Texto original: "give voice to their ethnic group, and call for a more inclusive nation and national discourse, one that acknowledges diversity and plurality".
} 


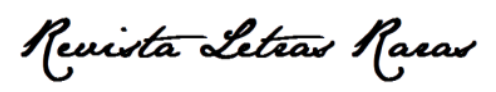

ISSN: 2317-2347 - v. 10, n. 4 (2021)

Todo o conteúdo da RLR está licenciado sob Creative Commons Atribuição 4.0 Internacional

o seu entendimento das análises feitas em cada capítulo, como dá ao projeto autoral um caráter mais interdisciplinar (p. 262). Ainda nessa perspectiva mais inclusiva, a obra, mesmo sendo direcionada a um público leitor da língua inglesa, quer como falantes nativos ou não, não apaga as línguas originais em que os romances foram escritos. Diante disso, Tosta apresenta os textos originais das obras escritas em português e em espanhol e oferece uma tradução ao inglês das passagens dos romances apresentados nas análises. Para tal, o autor ou faz a sua tradução dos trechos escolhidos ou utiliza a tradução existente de obras já traduzidas ao inglês, como é o caso de Malinche, A estranha nação de Rafael Mendes [The Strange Nation of Rafael Mendes] e Mestizo.

Por fim, Confluence Narratives: Ethnicity, History, and Nation-Making in the Americas é uma grande contribuição para os estudos interamericanos, para a literatura comparada e para o gênero 'narrativa de confluência'. A obra dá ao leitor conhecimento sobre esse gênero literário, cujo conceito é bem discutido e argumentado pelo autor, e permite que o leitor perceba como ele pontua os elementos históricos utilizados pelos/as romancistas/as para a construção da arquitetônica da obra, em que conteúdo, material e forma são um todo indissolúvel (BAKHTIN, 2002) ${ }^{19}$.

A análise das obras que levam em conta esses elementos constitutivos também aguçam a curiosidade do leitor e o desejo de ler os romances que foram analisados - a verve de educador de Tosta que motiva os leitores também a serem analistas críticos desses romances e de outros que compõem o gênero. A obra também é um convite a pesquisadores que queiram se debruçar sobre narrativas de confluência, tendo em vista a sua difusão nas literaturas das Américas (p. 262). Segundo Tosta, há dois tipos de projeto que são necessários à área: projetos que aumentem a "colaboração entre acadêmicos interamericanos nas Américas" e projetos que não apenas estudem, mas que "partam de diferentes lugares dos continentes americanos [para] ampliarem o escopo da área de estudos" (p. 263) ${ }^{20}$. Dessa forma, Confluence Narratives: Ethnicity, History, and NationMaking in the Americas é um convite a leitores e pesquisadores para participarem desse diálogo interamericano no mundo da arte e no mundo da vida.

\footnotetext{
19 BAKHTIN, M. O problema do conteúdo, do material e da forma na criação literária. In: BAKHTIN, M. Questões de literatura e de estética: a teoria do romance. Tradução de Aurora F. Bernardini et al. São Paulo: Hucitec; Annablume, 2002. p. 13-70.

20 Texto original: "collaborations between inter-American scholars throughout the Americas"; "originate from different locations in the American continents [to] broaden the scope of the field".
} 